OMAE2006-92465

\title{
A STATISTICAL APPROACH TO EXTREME ICE LOADS ON LIGHTHOUSE NORSTRÖMSGRUND
}

\author{
Lennart Fransson \\ Luleå University of Technology, Sweden
}

\author{
Jan-Eric Lundqvist \\ Swedish Meteorological and Hydrological Institute
}

\begin{abstract}
Data from full-scale measurements of ice loads on lighthouse Norströmsgrund has been analyzed using basic statistical methods. Questions like scaling, duration of ice interaction and correlation of extreme ice loads on different segments of the structure are discussed. Typical ice conditions in the Baltic Sea are described in general and the region is divided into areas with similar ice and ice movements. Indications of strong influence of structure diameter on the effective ice pressure were confirmed by results obtained on other lighthouses in the area. The result can be used in simulations of ice load probabilities for fixed vertical structures with small diameters located in the Baltic Sea.
\end{abstract}

\section{INTRODUCTION}

Ice conditions in the Baltic Sea have been monitored for many hundred years and are well described in the literature. Strong, landfast sea ice between Sweden and Finland was in the early days important for transportation with horse drawn sledges (Olaus Magnus, 1539). Nowadays, ice mapping and ice forecasting provides essential information for year-around shipping in the same area. Experiences of stationary off-shore structures in heavy ice concern however only a few northern lighthouses and channel markers. It has simply been too difficult and expensive to place fixed structures in such a hostile environment. Several structures have been damaged by ice forces from moving ice and ice-induced vibration is still a problem for the existing structures. Despite all the new worldwide information about ice/structure interactions, locating a fixed structure in the Baltic Sea is in general considered as costly and hazardous. When discussing suitable locations of off-shore wind generators along the coastline of the Baltic Sea, the potential of ice loads is essential. In this paper, selected data from full-scale measurements of extreme ice pressure on structures in the Baltic Sea are discussed. Simplified empirical design rules are challenged with a proposed method using statistics on ice crushing, climate and ice conditions.

\section{ICE CONDITIONS IN THE BALTIC SEA}

In the middle of December ice formation gradually starts off the coasts and off the outer archipelagos in the North. The weather and wind conditions varies a lot and new formed ice at sea often breaks up and becomes compacted at the fast ice edge and form a jammed brash barrier (a narrow belt of compressed shuga and brash ice). The ice normally freezes together and form a very thick ice cover compared with the surrounding fast ice. Later on the ice belt becomes wider, especially off the northeastern parts due to further ice formation. In connection with southerly winds the ice becomes further compacted with ridges.

When a cold weather period is established with north- or northeasterly winds the belt, often 20-30 nm wide, loosens from the coast and drifts out to sea. An ice field of consolidated $10-40 \mathrm{~cm}$ thick ice floes forms far out to sea. The opened area between the ice field and the coast is then rapidly covered by new ice which grow thicker and in a few days the ice is fairly level and $10-20 \mathrm{~cm}$ thick. The ice drift is mostly moderate southwesterly. If the cold weather remains for a week or longer the whole sea area, as normal in the middle of January, is totally covered by ice, mostly level. Ice thickness in the Gulf of Bothnia is at this time of the year typical $20-30 \mathrm{~cm}$ with areas of thicker ice. Rafted ice occur especially in the Bight of Skellefteå due to the southerly ice drift.

Sometimes in January strong southerly winds ahead of a temporarily mild air attack break up the thin ice in the South. Heavily northerly ice drift follows and the ice field is compressed towards the North forming ridges off the northern coast. In the southern part of the Bay of Bothnia wide areas of open water form. The weather in February and March varies but cold periods are dominating and the whole sea area is covered by ice. Wind conditions are decreased. Minor leads 
temporarily form along the coasts but are rapidly covered by new ice. In the central parts the ice field is fairly level and only minor ridges occur. The ice is gradually growing thicker and at the end of March max level ice thickness at sea is $40-60 \mathrm{~cm}$ in the North and 20-40 cm in the South. The ice drift is weak or moderate due to the thicker ice. Ridges are mostly formed off the coasts and often formed in old ice-breaker channels. Since year-around shipping was decided 1972 Swedish ice-breakers make ice channels along the Swedish coast and Finnish icebreakers along the Finnish. A wide coherent ice field forms in the central parts of the sea and small ice motions more often occur. The frequency of ridges and hummocks are greatest along the coasts, especially in the northern parts of the sea area where also the ice concentration is greatest. Areas with numerous pressure ridges and thicker ice occur.

In April mild air starts penetrating with southerly winds. Heavy ice pressures in the northern parts occur and new ridges are formed also in central parts of the sea area while leads and openings are formed in the southern. These leads and open areas are then partly filled up by drift ice from the North due to northerly winds or southgoing current. In these cases the ice field in the North starts breaking up into giant or vast and smaller ice floes. No significant ice pressure occur other than internal pressure between floes. These vast floes are often very thick with ridges and the floes obstruct the navigation at places during long time in May.

\section{FULL-SCALE MEASUREMENTS OF ICE LOADS AT LIGHTHOUSE NORSTRÖMSGRUND}

Ice loads and structural vibrations on lighthouse Norströmsgrund has been studied in many different ways already since it was built in 1971. The first winter in service severe vibrations and cracks in the concrete walls were observed and it was therefore decided to monitor the vibrations with accelerometers. These measurements and analysis by Engelbrektson (1977) lead to the conclusions that forces during ice crushing at certain velocities were saw-tooth shaped with a frequency close to the natural frequency of the lighthouse. Such strong vibrations caused dynamic amplifications of the stresses in the structure and were also responsible for damage on sensible equipment.

The first direct full-scale measurements of ice loads took place at Norströmsgrund 1987 when Hamburgische ShiffbauVesuchsanstalt GmbH (HSVA) developed and placed loadsensitive panels at the waterline (Wessels et al., 1989). In the European research project "Validiation on Low Level Ice Forces on Coastal Structures" (LOLEIF) which commenced 1998, ice loads on Norströmsgrund were measured simultaneously on nine panels covering about half the periphery. One of these panels was divided into eight individual load sensing areas. Much information and important results from these measurements have been published earlier (www.hydromod.de/loleif) and will not be repeated here. Instead three selected events from Jochmann \& Schwarz (1999, 2000) have been chosen to illustrate important characteristics of ice loads.
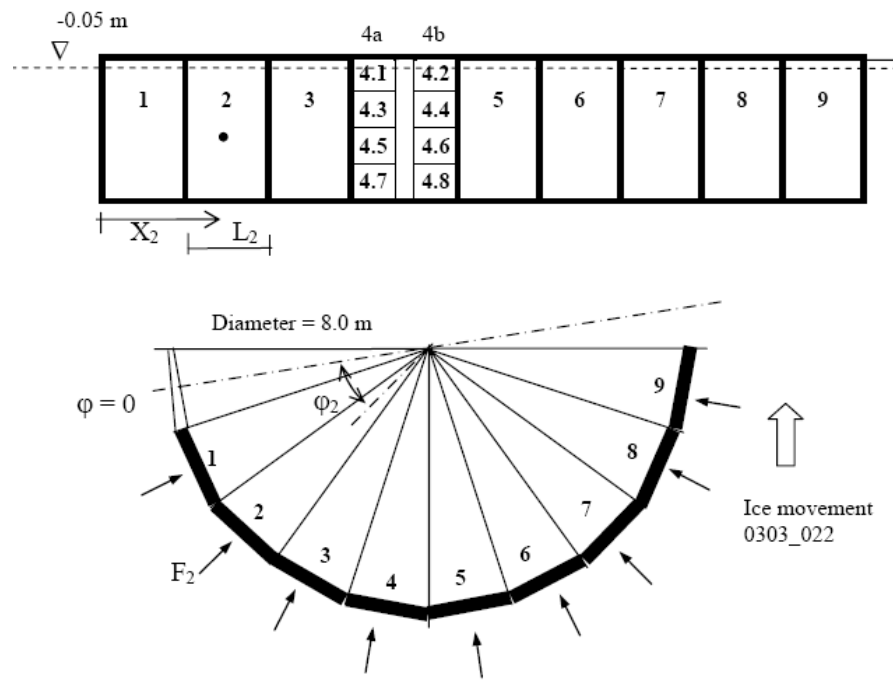

Figure 1. Lay-out of pressure sensors (1-9) and geometry of the lighthouse foundation.

\section{STATIC ICE LOADS}

Ice pressure under periods with static ice loads increases with the driving force and reaches a maximum shortly before the onset of ice movements. Similar loads are also recorded when an ice sheet stops against the structure due to insufficient driving force. In-frozen conditions or long time of high pressure leads to an almost perfect contact between the ice edge and the structure. Therefore it is safe to say that all segment loads are correlated and maximum ice pressure is reached more or less simultaneously along the contact area, see Fig. 2a. The amendment to Korzhavin's formula, where effective ice pressure is multiplied with $\sqrt{5(h / D)+1}$ (Afanesiev et al., 1971) has in numerous applications proved to describe the strong influence of aspect ratio $(D / h)$. Narrow structures, in comparison with the thickness of interacting ice sheets, have to deform ice in plane strain conditions and under high lateral confinement. It could also be argued that the horizontal size of unbroken ice sheets must be of importance since radial splitting of relatively large ice floes may take place at lower pressure levels. When ice is pressed towards a long vertical wall $(D / h=\infty)$ it is logical to expect a pressure that equals the unconfined compressive ice strength. Small scale laboratory tests of cold brittle ice usually yield high strength values when the end surfaces are made perfect. Ice edge contacts with most structures are assumed to introduce some stress concentrations that reduces the potential of maximum pressure. Substituting the expression by Afanasiev et al. (1971) with a power function results in a formula where the effective pressure $p_{0}$ can be calculated as

$$
p_{0}=k_{0} \sigma_{c}\left(\frac{D}{h}\right)^{-0.3} \quad(1 \leq \mathrm{D} / \mathrm{h}<20)
$$


Table 1. Data from the LOLEIF data base on selected events.

\begin{tabular}{|c|c|c|c|c|c|c|c|c|c|}
\hline \multirow{2}{*}{$\begin{array}{l}\text { Year } \\
\text { Data File }\end{array}$} & \multirow{2}{*}{$\begin{array}{l}\text { Duration }^{1} \\
\text { (s) }\end{array}$} & \multirow{2}{*}{$\begin{array}{l}\text { Ice } \\
\text { thickness }{ }^{2} \\
h(\mathrm{~m})\end{array}$} & \multirow{2}{*}{$\begin{array}{l}\text { Ice speed }^{3} \\
v\left(\mathrm{~ms}^{-1}\right)\end{array}$} & \multirow{2}{*}{$\begin{array}{l}\text { Ice move } \\
\text { direction }^{3} \\
\theta(\pi / 10)\end{array}$} & \multirow{2}{*}{$\begin{array}{l}\text { Wind } \\
\text { speed } \\
\left(\mathrm{ms}^{-1}\right)\end{array}$} & \multirow{2}{*}{$\begin{array}{l}\text { Air } \\
\text { temp } \\
\left({ }^{\circ} \mathrm{C}\right)\end{array}$} & \multicolumn{3}{|c|}{ Ice properties $^{4}$} \\
\hline & & & & & & & $\begin{array}{l}\begin{array}{l}\text { Ice } \\
\text { type }\end{array} \\
\end{array}$ & $\begin{array}{l}\text { Salinity } \\
\text { (ppt) }\end{array}$ & \begin{tabular}{|l} 
Strength \\
$(\mathrm{MPa})$
\end{tabular} \\
\hline 0303_021 & 300 & 0.26 & 0 & 5 & $5-8$ & -8 & Level & 0.6 & \begin{tabular}{|l|}
$1.1-1.4$ \\
\end{tabular} \\
\hline 0303_022 & 1200 & $0.26 \pm 0.04$ & 0.20 & $4 \frac{1}{2}$ & 8 & -8 & Level & 0.6 & \begin{tabular}{|l|}
$1.1-1.4$ \\
\end{tabular} \\
\hline 1004_1101 & 40 & 0.7 & 0.05 & 8 & $\sim 10$ & -1 & Level & $0.2-0.6$ & 1.4 \\
\hline
\end{tabular}

${ }^{1}$ Subset of recording, ${ }^{2}$ Drilled and registration $(0.14 \mathrm{~Hz})$ with sonar, ${ }^{3}$ Estimation from video recordings, ${ }^{4}$ Field tests, compressive load applied on samples cut from the ice sheet

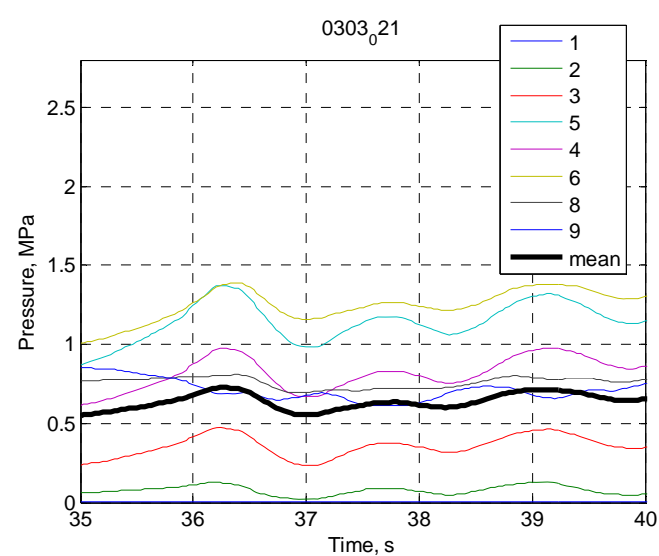

(a)
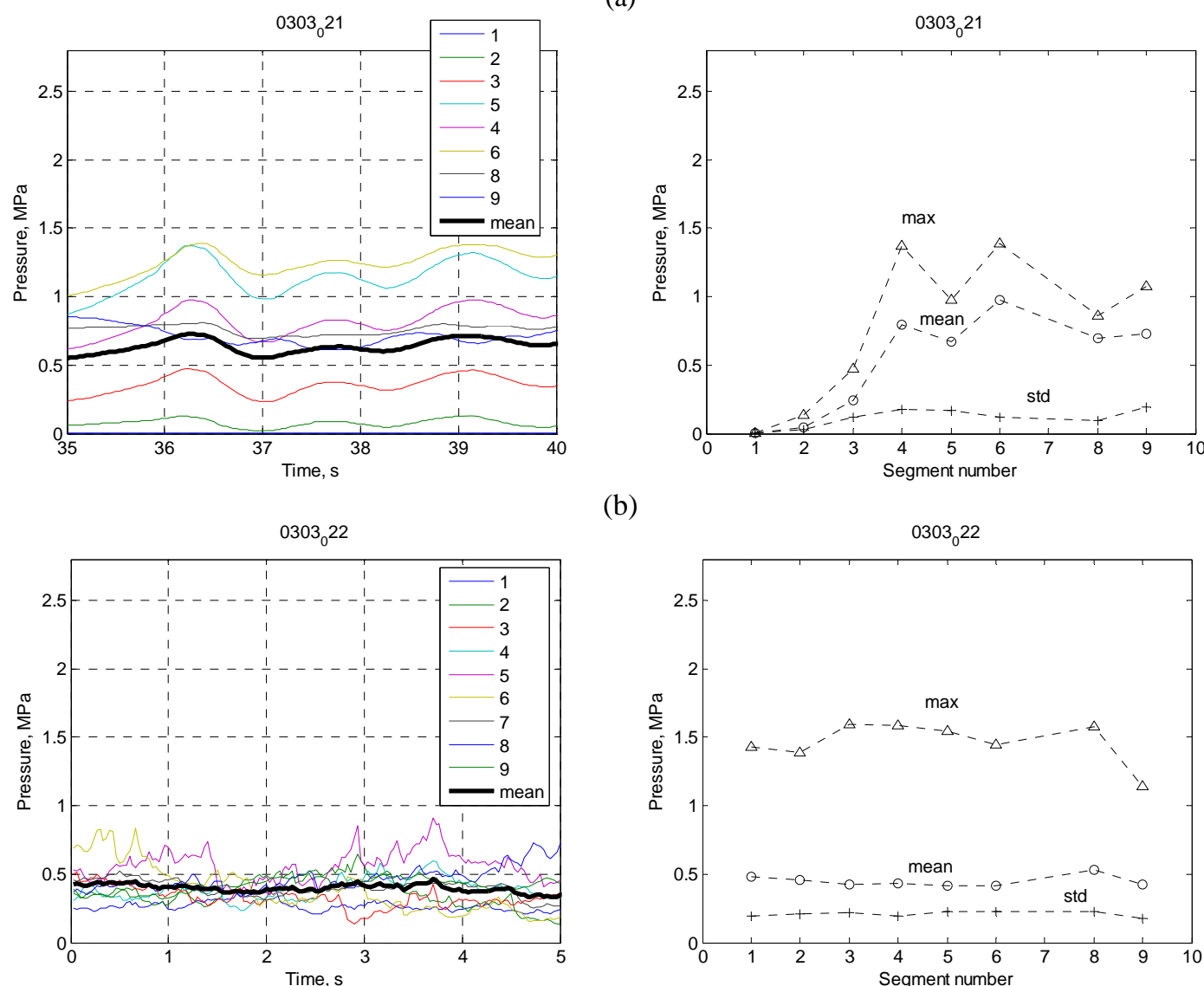

(b)

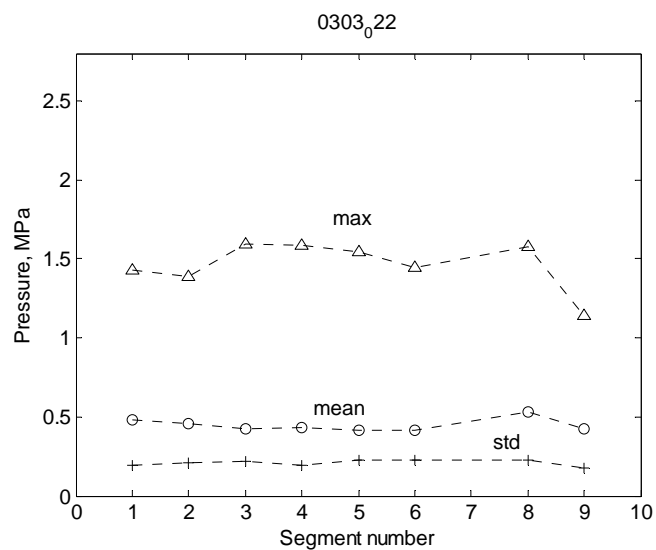

(c)
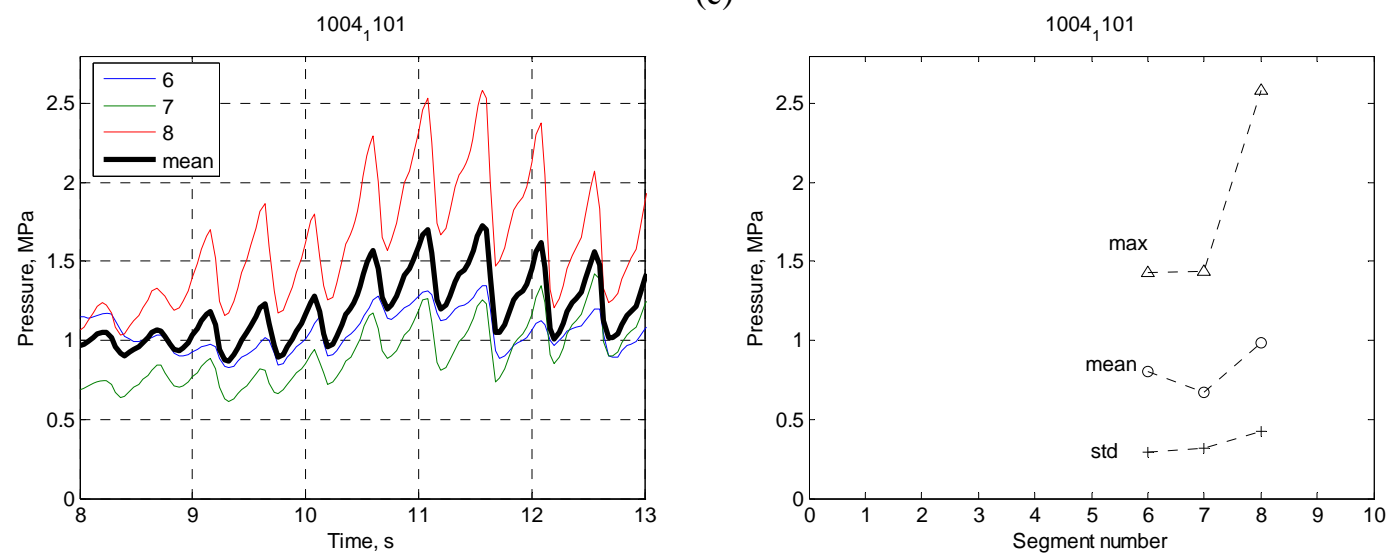

Figure 2. Static load (a), brittle ice crushing (b) and phase locked ice loads (c). Selected events from the LOLEIF data base. 
where $\sigma_{\mathrm{c}}=$ compressive strength of ice and $\mathrm{k}_{0}=\mathrm{a}$ constant that can be obtained from full-scale measurement of ice loads in combination with in-situ compression tests. It appeared that the maximum pressure in Fig. 2a was 1.0-1.5 MPa over the central contact area and decreased linearly at the side segments. The ice sheet was in this event already crushed against the lighthouse and $D / h=30$. In a more confined situation with unbroken ice of the same thickness, one would expect somewhat higher pressure and a cosine distribution.

\section{BRITTLE ICE CRUSHING}

When the surrounding ice sheet moved the interacting ice edge failed in a brittle crushing mode. For thin level ice brittle crushing took place at ice velocities in the range $0.1-0.6 \mathrm{~m} / \mathrm{s}$. Ice loads on different segments of the structure were uncorrelated and the maximum loads were reached nonsimultaneously, as shown in Fig. 2b. As a matter of fact, it appeared that the maximum load on a certain segment could only be reached if the nearby segments showed low load levels. Based on these results from the LOLEIF-project the following size dependent pressure $p$ was proposed:

$$
p=p_{0}\left(\frac{L}{h}\right)^{m}
$$

$p_{0}=$ maximum ice pressure on a contact area $A_{0}=h^{2}, L=$ contact length with the ice sheet and $m=$ scale exponent. The scale parameter was found to be $m=-0.24$ for Norströmsgrund when interacting with thin level ice (Fransson \& Olofsson, 2005). Bjerkås (2004) refer to investigations where $m$ is -0.3 to -0.1 for non-simultaneous failure mode when measured on the same structure. Maximum ice pressure perpendicular to the segments $(L / h=4.6)$ was about $1.5 \mathrm{MPa}$ relatively independent of registration angle, see Fig $2 b$. Maximum ice pressure $p_{0}$ can then be obtained from Eq. (2) as $p_{0}=2.2 \mathrm{MPa}$. With the assumption that aspect ratio effects are small $p_{0}=\max \left(\sigma_{c}\right)$ for the total interacting ice volume. It is therefore natural that the measured ice strength on an arbitrary collected ice volume was smaller, see Table 1.

\section{INFLUENCE OF CRUSHING DISTANCE}

The maximum pressure $p_{0}$ or maximum ice strength is considered as dependent on crushing distance. Exposure of ice can be calculated from the estimated travel length of ice sheets with its ice thickness close to the estimated design ice thickness. The probability density function of ice pressure on a small area proved to be of Weibull type where high pressures after a certain travel length were represented by a negative exponential slope. Based on this probability, pressures obtained from full-scale measurements are assumed to be exceeded as the interaction proceeds as indicated in Fig.
3. Maximum pressure after a certain travel length $p_{0}^{T}$ is then calculated

$$
p_{0}^{T}=p_{0}(1+k \log (n T)),
$$

where $T=$ total travel length of ice sheets within the structures lifetime, $k$ and $n$ are empirical constants. When analysing eventual influence of distance on recorded ice loads, even small variations in ice thickness must be considered. Increasing thickness or more uniform and plane ice both results in increasing loads.

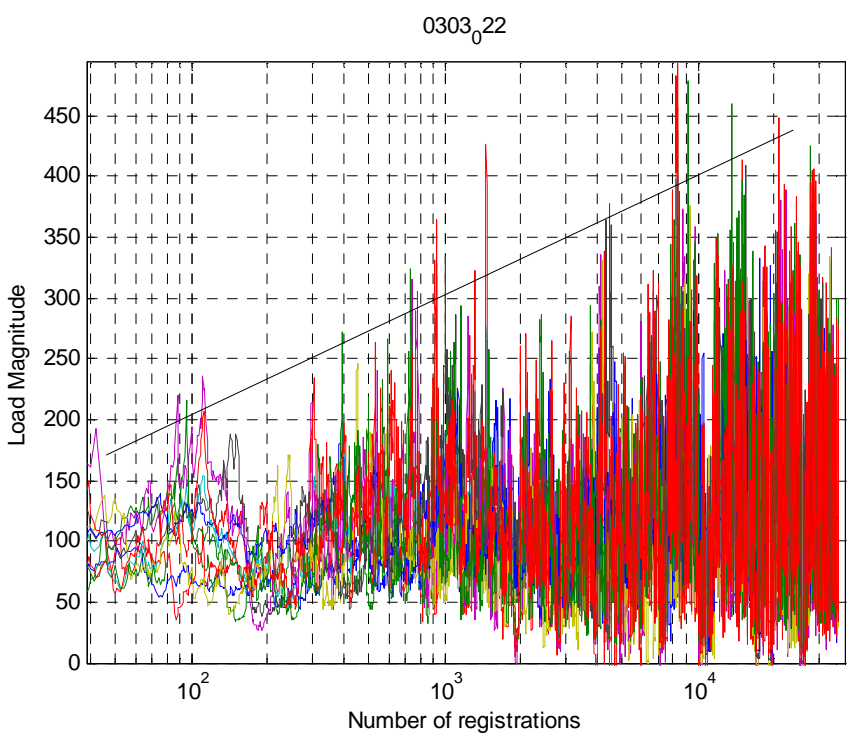

Figure 3. Indication of crushing distance effect on recorded ice loads in event 0303_022.

\section{PHASE LOCKED ICE LOADS}

When a flexible structure is interacting with thick ice, structure movements at the waterline alter the crushing mode of ice and causes phase locking of all crushing activities along the structure width. The scale exponent in Eq.(2) will thus be close to $\mathrm{m}=0$ but the pressure distribution becomes different. Even if the manually measured ice thickness was somewhat uncertain in event 1004_1101, it is clear that the pressure peaks were exceptionally high when ice loads were oscillating at a constant frequency, see Fig. 2c. It is also evident that the individually measured loads were synchronized during short time periods. Seen over the whole measuring time pairs of segment pressures were more correlated than usual even though there were periods of uncorrelated pressures. In this event the whole structure was moving and it is assumed that the increasing part of the saw-tooth curve was due to elastic deformation of interacting ice. From this assumption follows that the maximum pressure probably was cosine distributed with a maximum pressure in the moving direction. Integration 
along the contact area then results in the following average pressure on a cylindrical structure:

$$
p=\frac{2}{\pi} p_{0}
$$

\section{INFLUENCE OF COMPLIANCE}

In the case of cylindrical foundations it is obvious that even the smallest change of the diameter $\mathrm{D}$ has a substantial influence on the ratio of stiffness to ice load. Ice load can at the most be proportional to the projected area and $\mathrm{D}$, whereas stiffness is proportional to $\mathrm{D}^{4}$. Also bending and shear capacity increases more rapidly than the ice load as the structure is made bigger, see Table 2. If there is an existing structure that has survived in the area over the past 30 winters it is most likely that a similar but bigger structure also will survive. This fact makes designing of off-shore structures in the Baltic easier than in undeveloped ice infested areas.

Table 2. Effect of diameter on foundation properties.

\begin{tabular}{|cc|}
\hline $\begin{array}{c}\text { Property of a cylindrical } \\
\text { foundation }\end{array}$ & $\begin{array}{c}\text { Magnitude } \\
D=\text { diameter }\end{array}$ \\
\hline bending stiffness & $D^{4}$ \\
bending capacity & $D^{3}$ \\
shear capacity & $D^{2}$ \\
projected area & $D^{1}$ \\
ice pressure & $D^{\mathrm{m}}$ \\
\hline
\end{tabular}

For economical reasons most foundations have been compliant compared to thick and homogeneous ice sheets. Iceinduced vibrations and resonant ice loads have proved to be difficult to take care of. In general flexible structures tend to get a more uniform and simultaneously changing ice pressure at the contact area, and all the narrow vertical structures have to be designed for that.

\section{DOCUMENTATION OF ICE PRESSURE IN THE BALTIC SEA}

Over the years since the first off-shore lighthouse was deployed there have been several cases where foundations have been moved by the ice. Lighthouses in the ice have probably intentionally been underdesigned because of the vast costs and the small risk of human injuries. On the other hand ice mechanics and ice loads were poorly understood at the time. Above all the narrow structures $(D<3 \mathrm{~m})$ have suffered from damage due to underestimation of ice loads. Ice pressures in Table 3 is a compilation of estimated pressures on damaged structures and extreme full-scale measurements of ice pressures on lighthouses. Details about the overloading events and further references are found in Bjerkås (2006).
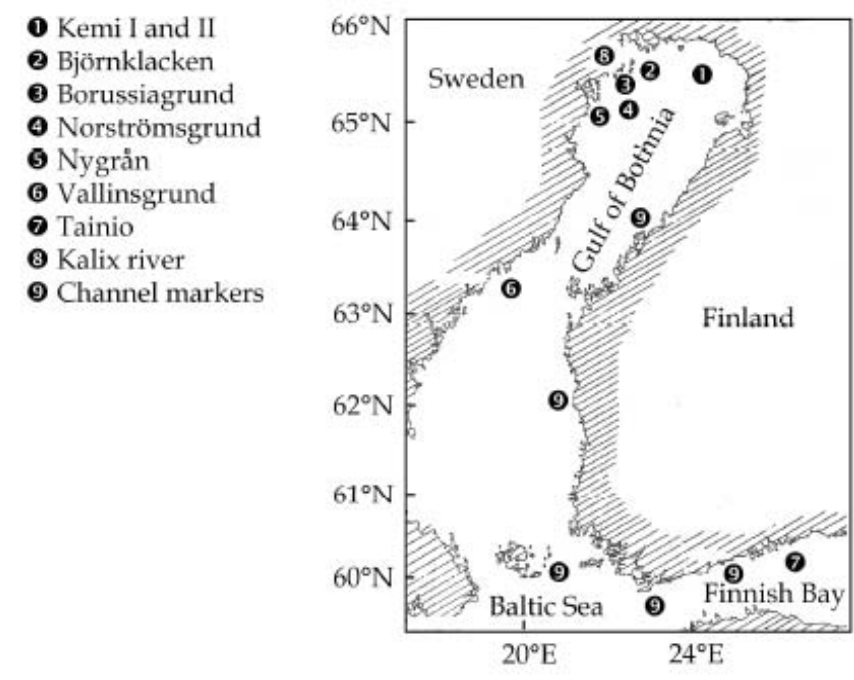

Figure 4. Location of lighthouses in the Baltic Sea, Bjerkås (2006).

Table 3. Measured ice pressures on lighthouses in the Baltic Sea.

\begin{tabular}{|l|llll|}
\hline Lighthouse & $\begin{array}{l}\text { h } \\
\text { m }\end{array}$ & $\begin{array}{l}\text { D } \\
\text { m }\end{array}$ & D/h & $\begin{array}{l}\text { P } \\
\text { MPa }\end{array}$ \\
\hline Kemi I, steel & 0.9 & 1 & 1.11 & 5 \\
Kemi I, conc & 0.9 & 5.8 & 6.44 & 1.8 \\
Kemi I, conc & 0.8 & 5.8 & 7.25 & 1.7 \\
Kemi II, old & 1 & 1 & 1.00 & 4.3 \\
Norströmsgrund & 1 & 7.5 & 7.50 & 1.3 \\
Norströmsgrund & 0.6 & 8 & 13.33 & 1.2 \\
Norströmsgrund & 0.3 & 8 & 26.67 & 1.4 \\
Tainio & 0.7 & 3.5 & 5.00 & 1.9 \\
Vallinsgrund & 0.7 & 2.9 & 4.14 & 3.4 \\
Björnklacken & 1.2 & 2.9 & 2.42 & 3.1 \\
\hline
\end{tabular}

Eq (1), (2) and (3) furnished with constants from full-scale measurements gives the following expression for effective ice pressure $p_{\text {eff }}^{T}$ as a function of foundation diameter:

$$
p_{\text {eff }}^{T}=k_{0} \sigma_{c}(1+k \log (n T))\left(\frac{D}{h}\right)^{-0.3+m}
$$

If regions are classified due to the total travel length of the ice sheets within a structures life length it is possible to obtain typical values on all the constant in Eq.(5). Proposed constants in Table 4 may serve as a basis for discussion. The strong influence of structure diameter on the effective ice pressure is shown in Fig. 5. 
Table 4. Proposed constants for fictitious ice regions in the Baltic sea.

\begin{tabular}{|c|cccc|}
\hline $\begin{array}{c}\text { Type of ice } \\
\text { region }\end{array}$ & $\begin{array}{c}k_{0} \sigma_{c} \\
(\mathrm{MPa})\end{array}$ & $k \log (n T)$ & $m$ & $\begin{array}{c}h \\
(\mathrm{~m})\end{array}$ \\
\hline Archipelago & 6.0 & 0 & 0 & 1 \\
Outer skerries & 5.5 & 0 & 0.24 & 1 \\
Deep sea & 5.5 & 0.1 & 0.24 & 1 \\
\hline
\end{tabular}

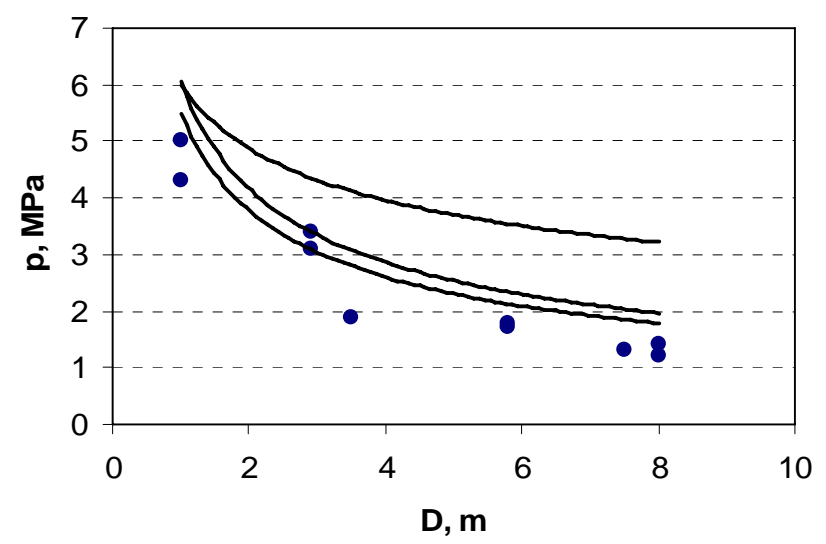

Figure 5. Pressure vs. diameter D of lighthouses calculated with Eq.(5) and set of constants in Table 4. Ice pressures from full-scale measurements in the Baltic Sea (Table 3) are shown as circular dots.

\section{DISCUSSION AND CONCLUSIONS}

The potential of high nominal ice pressures varies with locations at the Baltic Sea. Low salinities and uniform ice covers makes the northern archipelago a candidate for high ice pressures. Cold and stable ice surrounds and freeze to the structures but may also move slowly due to thermal expansion or accelerate when open channels are formed. The governing ice failure mode will then be associated with a high uniform static pressure on most of the ice contact area. High global loads at the onset of ice movements were also obtained at Norströmsgrund. The effect of structure width on the measured ice pressures on lighthouses shown in Fig. 5 is remarkable. Global loads for the most narrow structures $(D=1 \mathrm{~m})$ were calculated from measured accelerations where a dynamic amplification due to strong vibrations was evident. It is therefore possible that the ice pressure for the narrowest structures and thus the appearing diameter effect are slightly overestimated.

Verified size effect in brittle crushing is, in the authors opinion, a result of the balance between large cracks in the ice sheet and the concentration of high pressure zones (Daley et al.,1998) that drives the fracturing process. When pressure is equally distributed over a wide band large fracturing takes place at low pressure level. High effective pressure on a certain contact area might only be possible under a high degree of confinement and before major damage of the incoming ice sheet. Maximum pressure and average pressure level are strongly dependent on the prevailing stress conditions. Stress conditions are not necessarily a function of aspect ratio. The existence of radial cracks and boundary conditions of the interacting ice floe might be equally important parameters. The probability of extreme ice pressures depends on so many variables that it is difficult to make estimates based on too short measuring times. Long exposure time of ice should lead to higher design pressures, but the proposed logarithmic relationship Eq. (3) might be an overstatement. From a philosophical point of view it is hard to accept that there is no upper limit for effective ice pressures on a certain structure. Careful analysis of long lasting load measurements and simultaneously recorded ice thickness are needed in order to establish a more reliable ice pressure probability.

Ice-induced vibrations can not be avoided in an economically justified design of most off-shore foundations placed in the northern parts of the Baltic Sea. Damping systems are available with the ability to mitigate vibrations and most unwanted dynamic magnification of structural stresses. Observed phase-locked ice pressures were locally substantially higher than the expected compressive strength. Unfortunately only three ice loads could be registered in event 1004_1101. Pressure distribution associated with oscillations is not well understood and will be an interesting topic for further studies.

\section{REFERENCES}

Afanasiev, V.P., Dolgopolov, Y.V. and Shaishtein, Z.I. 1971. Ice pressure on individual marine structures. In Ice Physics and Ice Engineering, Israel Program for Scientiffic Translations, 1973, 50-68.

Bjerkås, M. 2006. Ice actions on offshore structures. Doctoral Thesis. Norwegian University of Science and Technology, Trondheim, Norway (to be published).

Bjerkås, M. 2004. Global design ice load dependence on failure mode. Proceedings ISOPE'04, 871- 877.

Daley, C., Tuhkuri, J., and Riska, K. 1998. The role of discrete failures in local ice loads. Cold Regions Science and Technology, vol 27, 197-211.

Engelbrektson, A. 1977. Dynamic ice loads on a lighthouse structure. Proceedings POAC'77, vol. 2, 654-663.

Fransson, L. and Olofsson, T. 2005. On scaling of the maximum pressure on a vertical foundation. Proceedings POAC'05, vol. 1, 341-352.

Jochmann P. and Schwarz, J. 1999. Ice force measurements at lighthouse Norströmsgrund - Winter 1999. LOLEIF Report No 5. Hamburgische SchiffbauVersuchsanstalt GmbH, Hamburg, 48 p. + App.

Jochmann P. and Schwarz, J. 2000. Ice force measurements at lighthouse Norströmsgrund - Winter 2000. LOLEIF Report No 9. Hamburgische SchiffbauVersuchsanstalt GmbH, Hamburg, 64 p. + App. 